\title{
3D Printed Reactors and Kessil Lamp Holders for Flow Photochemistry: Design and System Standardization
}

\author{
Matthew R. Penny, Stephen T. Hilton* \\ UCL School of Pharmacy, 29-39 Brunswick Square, London WC1N 1AX \\ † Electronic supplementary information (ESI) available \\ *Corresponding author: s.hilton@ucl.ac.uk
}

Matthew R. Penny: https://orcid.org/0000-0003-3572-1783

Stephen T. Hilton: https://orcid.org/0000-0001-8782-4499 


\begin{abstract}
A low-cost 3D printed standardized flow-photochemistry setup has been designed and developed for use with a pressure-driven flow system using photochemistry lamps available in most laboratories. In this research, photochemical reactors were 3D printed from polypropylene which facilitated rapid optimization of both reactor geometry and experimental setup of the lamp housing system. To exemplify the rapidity of this approach to optimization, a Kessil LED lamp was used in the bromination of a range of toluenes in the $3 \mathrm{D}$ printed reactors in good yields with residence times as low as 27 seconds. The reaction compared favorably with the batch photochemical procedure and was able to be scaled up to a productivity of $75 \mathrm{mmol} \mathrm{h}^{-1}$.
\end{abstract}

\title{
Key Words:
}

3D Printing, Additive Manufacturing, Flow Chemistry, Photochemistry, Fluidics

\section{Article Highlights:}

- We demonstrate the rapid optimization of 3D printed polypropylene reactors for flow photochemistry.

- We show that the reactors can be used with a standardized 3D printed Kessil lamp set up .

- We show how the system can be used in an exemplary photochemistry reaction for the bromination of a range of toluenes and that it can be easily scaled. 


\section{Introduction}

Photochemical reactions have received growing interest in the literature as a result of the fact that the use of light allows for greater selectivity in activation of catalysts, especially when combined with an appropriate and finely tuned combinations of wavelength and photocatalyst. Recent research in the area includes selective modification of biological molecules [1, 2], tandem reactions using multiple catalysts [3, 4] and phototelectrochemistry [5]. Although there have been many novel transformations and photocatalysts developed, there remains a fundamental problem with variation in the reports of these reactions due to the plethora of light sources and experimental setups which has led to the introduction of a number of different reported set-ups and equipment [6-13]. The issue of repeatability is receiving attention in the literature along with the often-overlooked aspect of treating light as a "reagent" [14].

Along with the increase in photochemistry publications over the last decade, the application of photochemistry to continuous flow has also received significant attention due to the significant benefits that it offers [15-19]. These include: improved irradiation of the reaction mixture due to a shorter path length in flow reactors compared to batch vessels; improved reaction selectivity; fast heat exchange (important in removing heat generated by light); fast mixing of reagents and fast quenching of reactive intermediates; multiphase chemistry and easier scale-up of reactions. The direct comparison of reaction efficiency with batch is discussed in the literature and highlights the need for more research in this area and a greater understanding of the experimental setups, particularly the power and wavelength of the light source [20].

Due to the fact that much of recent research in photochemical methods involves lower energy visible light, inexpensive and readily available LED lamps have frequently been used in undergraduate laboratory experiments [21-24]. As flow chemistry is increasingly taught in practical courses, the move to flow photochemistry is made simpler by the availability of these lamps which can be used with existing flow equipment and transparent tubing. In addition, some groups have detailed construction of in-house developed photochemistry apparatus [23] and 3D printed reactors for use in practical classes [21]. 
As a result of the challenges in standardizing and reporting on photochemical setup and reactions in flow chemistry, combined with our research into rapid prototyping and equipment development using 3D printing, we sought to develop a standardized housing for readily available LED lamps that could be used in combination with 3D printed flow photochemistry cells [25-29]. The aim of this was to introduce a low cost, small footprint system that could be combined with existing laboratory equipment to allow researchers to investigate photochemical reactions in flow. The use of 3D printing meant that we could develop a bespoke add-on to our existing flow chemistry equipment for the optimization of photochemical reactions. The circular shape of our existing previously reactors, [29] meant that these would be of a suitable standard size for LED array lamps in order to maximise irradiance as they were already circular and so would matched the irradiance output from a Kessil lamp. The proposed set-up was therefore designed to integrate with our pressure driven continuous flow system and the photochemistry set up could be simply added to the system as shown below (Figure 1). The aim was to utilize and optimize our existing CDRs for flow photochemistry and to develop a suitable 3D printed housing to hold a Kessil lamp above the reactor where the distance could be easily optimized (Figure 1).
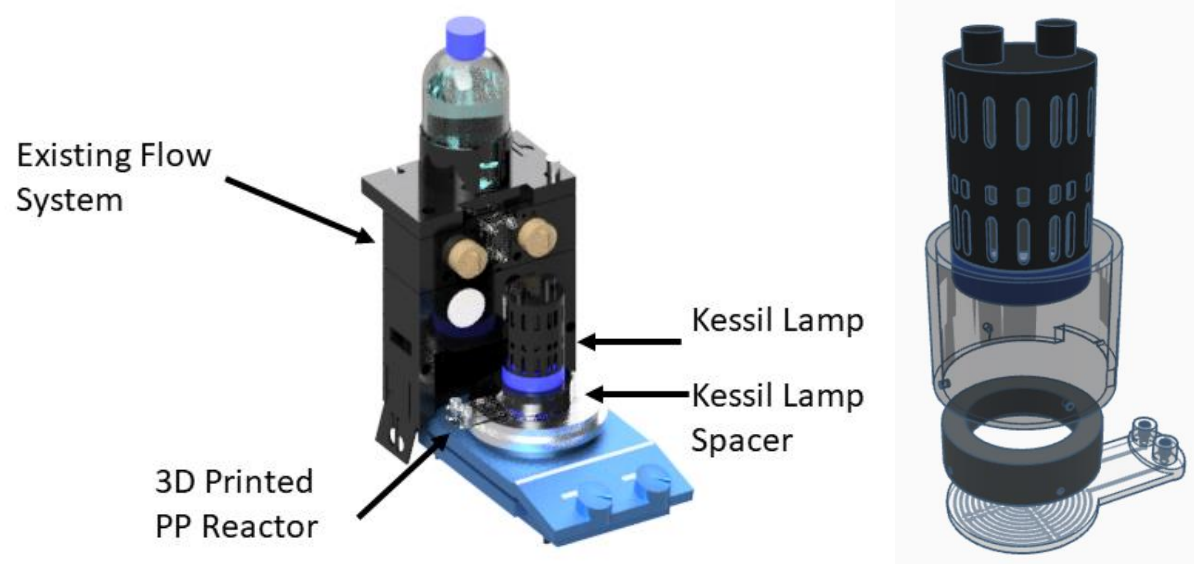

Figure 1 - Proposed Continuous Flow Photochemistry system for use with existing Kessil Lamps (left) and exploded view (right) showing the proposed lamp set up above the 3D printed reactor. 


\section{Results and Discussion}

We selected a simple benzylic bromination reaction to assess the applicability of our pressure driven flow photochemistry system to demonstrate exemplification and act as a standard for comparison [30] (Scheme 1).<smiles>COC(=O)CCc1ccccc1</smiles>

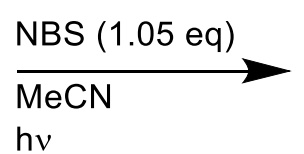<smiles>COC(=O)CC(Br)c1ccccc1</smiles>

\section{Scheme 1 - Selected radical bromination photochemistry reaction for reactor testing.}

We initially focused on stereolithography (SLA) 3D printing for reactor production due to the transparent nature of resultant prints. However, our initial experience with using 3D printed SLA photochemical reactors was problematic as the heat given off from the lamp causing expansion and cracking of the reactor. Although polypropylene (PP) has been shown to have good transparency to near-UV light [31], we believed that the walls of our previously reported circular disk reactor (CDR) could be easily narrowed to allow more light to reach the reaction. We first selected a Kessil lamp spacer distance of $25 \mathrm{~mm}$ in order to provide a suitable distance for further optimization studies.

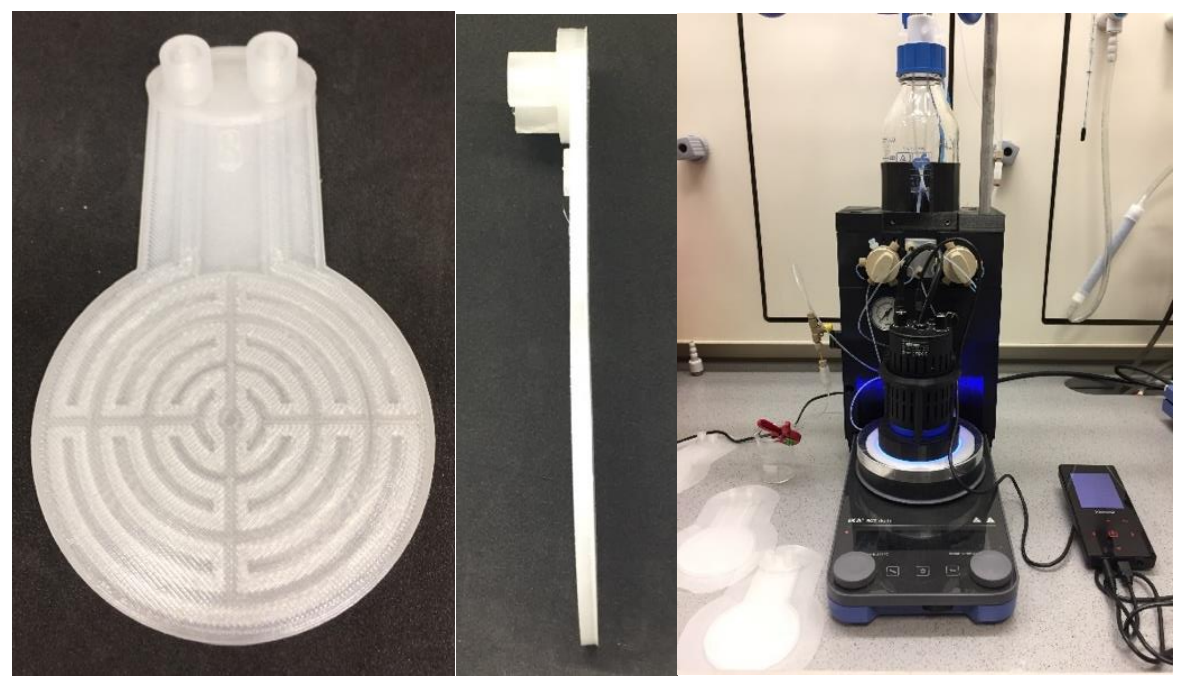

Figure 2 - Circular disc reactor (CDR) adapted for photochemistry (left and middle image); Initial setup of realized flow photochemical apparatus (right image) 
Initially, a $0.25 \mathrm{M}$ acetonitrile solution of methyl hydrocinnamate and NBS were passed through the photoCDR at $1.0 \mathrm{~mL} / \mathrm{min}$, affording the brominated product with no starting material observed (Table 1). Increasing the concentration to $0.5 \mathrm{M}$ and reducing the residence time from 2.3 minutes to 26 seconds resulted in a marginal decrease in conversion. An increase in concentration above $0.5 \mathrm{M}$ was not considered due to the poor solubility of succinimide which could impede the flow through the capillary and therefore affect the flow rate. To solve this issue, the capillary was back-flushed with acetone after each reaction [29].

Table 1 - Initial results

\begin{tabular}{ccccc} 
Entry & Concentration & $\begin{array}{c}\text { Flow } \\
\text { Rate } \\
\text { (mL/min) }\end{array}$ & $\mathbf{t}(\mathbf{s e c})$ & $\begin{array}{c}\text { Conv. } \\
(\%)\end{array}$ \\
\hline $\mathbf{1}$ & 0.25 & 1.01 & 137 & 100 \\
$\mathbf{2}$ & 0.5 & 1.01 & 137 & 98 \\
$\mathbf{3}$ & 0.5 & 1.90 & 73 & 99 \\
$\mathbf{4}$ & 0.5 & 5.40 & 26 & 90
\end{tabular}

At this stage, we observed a trace amount of dibrominated product in the crude ${ }^{1} \mathrm{H}$ NMR spectrum and so, we decided to optimize the distance of the lamp from the reactor. The spacer was designed to sit directly on top of the reactor to give a more reliable distance between the lamp and the reaction. Lamp stands with a range of distances (Table 2) were 3D printed as well as an external collar (Supplementary information) to prevent the operator being exposed to light emitted from the photoCDR and hotplate underneath. The efficiency of the bromination reaction was evaluated at 6 different distances (Table 2). Although the trend observed was as expected, 3D printing of the spacers allowed optimization to be carried out quickly and demonstrates the benefits of such an approach, which given the significant implications on photon flux, is often lacking in the literature. It was decided that a distance of $30 \mathrm{~mm}$ was to be used so that any improvements in reaction efficiency due to subsequent modifications would be discernable. 


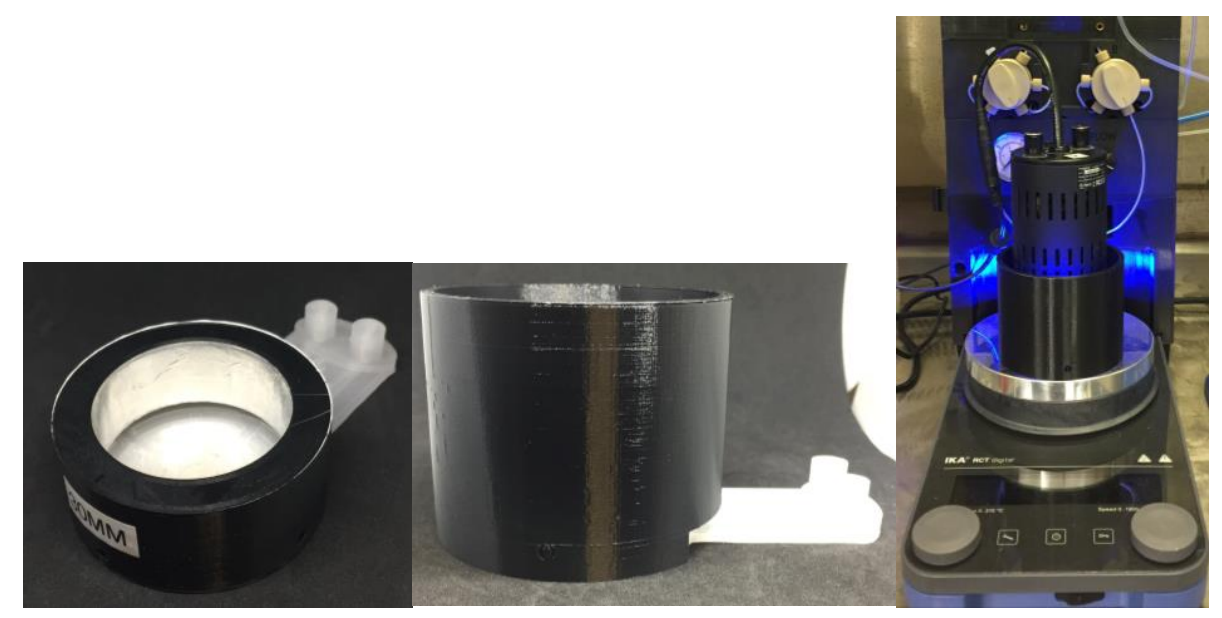

Figure 3-3D printed lamp holder for distance optimization (shown with reflective internal surface)

Table 2 - Distance optimization

\begin{tabular}{ccccc} 
Entry & $\begin{array}{c}\text { Distance } \\
(\mathbf{m m})\end{array}$ & $\begin{array}{c}\text { Flow Rate } \\
(\mathbf{m L} / \mathbf{m i n})\end{array}$ & $\mathbf{t}(\mathbf{s e c})$ & $\begin{array}{c}\text { Conv. } \\
(\%)\end{array}$ \\
\hline $\mathbf{1}$ & 50 & 5.10 & 27 & 2 \\
$\mathbf{2}$ & 40 & 5.19 & 27 & 31 \\
$\mathbf{3}$ & 30 & 5.15 & 27 & 69 \\
$\mathbf{4}$ & 20 & 5.10 & 27 & 88 \\
$\mathbf{5}$ & 15 & 5.09 & 27 & 100 \\
$\mathbf{6}$ & 10 & 5.09 & 27 & 100
\end{tabular}

As can be seen in Figure 3, the photochemistry reactions were conducted with the CDR situated directly on top of an IKA RCT Digital magnetic stirrer hotplate which has a reflective surface. The effect of this was compared to an older hotplate resulting in less than half the conversion. Whereas the mirror directly underneath the CDR had an improvement, the effect of a reflective surface around the inside of the lamp holder had a greater effect on the reaction conversion. The combination of both mirror and reflective lamp stand resulted in complete conversion (Table 3 and Supplementary information). 


\section{Table 3}

Material

HPLC Conversion (\%)

\begin{tabular}{cc}
\hline RCT Digital & 67 (average, $\mathrm{n}=4$ ) \\
Old RCT Basic & 31 \\
Black card & 8 \\
Mirror & 70 \\
$\begin{array}{c}\text { Internal Reflective Lamp } \\
\text { Holder (with black card } \\
\text { underneath) }\end{array}$ & 87 \\
Mirror + Reflective Lamp \\
Holder
\end{tabular}

Due the ease with which new reactor designs can be prepared using 3D printing, we next sought to optimize the CDR internal dimensions. A range of reactor designs were printed to investigate the effect of channel width and height as well as the thickness of polypropylene above and below the reactor channels (Figure 4 and Table 4).
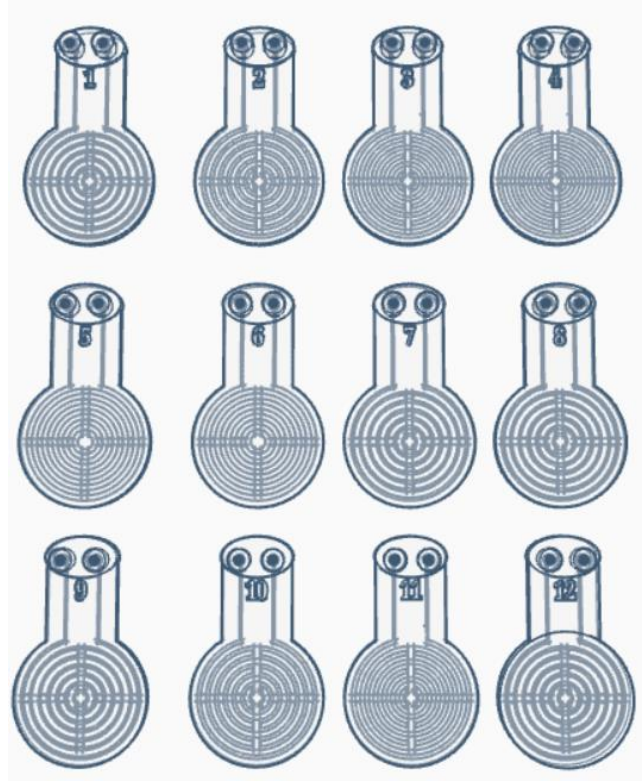

Figure 4 - Designs of flow paths used for the 3D printed reactors (reactors R1R12). 
Table 4 - Reactor dimensions

\begin{tabular}{|c|c|c|c|c|c|c|}
\hline \multirow{2}{*}{ Reactor No } & \multicolumn{2}{|c|}{ Channel } & \multirow{2}{*}{$\begin{array}{l}\text { Height } x \\
\text { width }\end{array}$} & \multicolumn{2}{|c|}{ Distance of channels } & \multirow{2}{*}{$\begin{array}{c}\text { Total (top } \\
\& \\
\text { bottom) }\end{array}$} \\
\hline & Width & Height & & From Top & $\begin{array}{c}\text { From } \\
\text { Bottom }\end{array}$ & \\
\hline R1 & 3.00 & 1.00 & 3.00 & 1.25 & 1.00 & 2.25 \\
\hline $\mathbf{R 2}$ & 3.50 & 1.00 & 3.50 & 1.25 & 1.00 & 2.25 \\
\hline R3 & 3.75 & 0.75 & 2.81 & 1.50 & 1.00 & 2.50 \\
\hline $\begin{array}{c}\text { R4 (same as } \\
\text { R3) }\end{array}$ & 3.75 & 0.75 & 2.81 & 1.50 & 1.00 & 2.50 \\
\hline R5 & 1.50 & 0.75 & 1.13 & 1.50 & 1.00 & 2.50 \\
\hline R6 & 1.50 & 0.75 & 1.13 & 1.25 & 1.25 & 2.50 \\
\hline R7 & 3.00 & 1.00 & 3.00 & 1.50 & 0.75 & 2.25 \\
\hline R8 & 3.00 & 0.75 & 2.25 & 1.50 & 1.00 & 2.50 \\
\hline $\mathbf{R 9}$ & 3.00 & 1.00 & 3.00 & 1.00 & 1.25 & 2.25 \\
\hline R10 & 3.50 & 1.00 & 3.50 & 1.50 & 0.75 & 2.25 \\
\hline R11 & 3.75 & 0.75 & 2.81 & 1.25 & 1.25 & 2.50 \\
\hline R12 & 3.00 & 1.50 & 4.50 & 3.00 & 2.50 & 5.50 \\
\hline
\end{tabular}

Given the observation that reflection of light from underneath the CDR is beneficial, it is not surprising that the thickness of polypropylene above the CDR channels has less of an effect on the reaction efficiency. This can be observed by the conversion achieved using reactor R12 which had twice the thickness of polypropylene above and below any of the adapted CDRs but with a larger internal volume. Whereas there is a correlation between conversion and the area of the reactor channel cross-section, a larger reactor volume and therefore longer residence time is the simpler explanation for the observed increase in reaction conversion (Table 5). 


\begin{tabular}{|c|c|c|c|c|c|c|}
\hline Reactor No & $\begin{array}{c}\text { Surface } \\
\text { area } \\
\left(\mathbf{m m}^{2}\right)\end{array}$ & $\begin{array}{c}\text { Cross } \\
\text { section } \\
\text { area } \\
\left(\mathrm{mm}^{2}\right)\end{array}$ & $\begin{array}{l}\text { Reactor } \\
\text { vol. }\left(\mathrm{cm}^{3}\right)\end{array}$ & $\begin{array}{l}\text { Flow Rate } \\
\text { (mL/min) }\end{array}$ & $\begin{array}{c}\text { Residen } \\
\text { ce time } \\
\text { (sec) }\end{array}$ & $\begin{array}{c}\text { Conv. } \\
(\%)\end{array}$ \\
\hline R1 & 2.31 & 3.00 & 2.31 & 5.15 & 27 & 86 \\
\hline R2 & 2.69 & 3.50 & 2.69 & 5.05 & 32 & 98 \\
\hline R3 & 3.01 & 2.81 & 2.26 & 5.15 & 26 & 88 \\
\hline R4 (same as & 3.01 & 2.81 & 2.26 & 5.19 & 26 & 87 \\
\hline R5 & 2.01 & 1.13 & 1.51 & 5.05 & 18 & 39 \\
\hline R6 & 2.01 & 1.13 & 1.51 & 5.03 & 18 & 39 \\
\hline R7 & 2.31 & 3.00 & 2.31 & 5.22 & 27 & 56 \\
\hline R8 & 2.31 & 2.25 & 1.73 & 5.16 & 20 & 32 \\
\hline $\mathbf{R 9}$ & 2.31 & 3.00 & 2.31 & 5.15 & 27 & 66 \\
\hline R10 & 2.69 & 3.50 & 2.69 & 5.18 & 31 & 91 \\
\hline R11 & 3.01 & 2.81 & 2.26 & 5.11 & 32 & 85 \\
\hline $\begin{array}{l}\text { R12 (thick- } \\
\text { walled } \\
\text { reactor) }\end{array}$ & 2.31 & 4.50 & 3.47 & 5.04 & 41 & $\begin{array}{c}100 \text { (by } \\
\text { NMR) }\end{array}$ \\
\hline
\end{tabular}

With the optimized conditions and reactors in hand, we turned our attention to the reaction of a series of toluene substrates (Table 6). The conditions afforded benzyl bromides in good yields and selectivities, but for more challenging benzyl bromides a higher residence time was required to obtain analogous yields. When a longer residence time was required (method B), the benzyl bromide was often isolated with small amounts of the dibrominated product, but this could be easily overcome by using the short residence time of method $A$ affording only monobrominated products (Table 6). 


\section{Table 6}

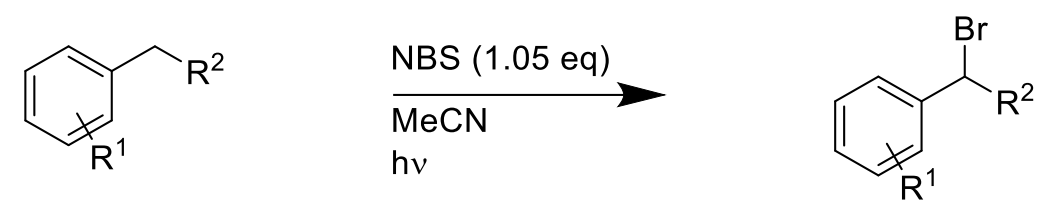

Method $\begin{gathered}\text { Residence } \\ \text { Time }\end{gathered}$
$\begin{gathered}\text { Yield } \\ \text { (\%) }\end{gathered}$ Dibromination


11<smiles>BrCc1ccc(Br)cc1</smiles>

12<smiles>O=[N+]([O-])c1ccc(CBr)cc1</smiles>

13<smiles>CCOc1ccc(CBr)cc1</smiles>

B

B

B
$2.7 \mathrm{~min}$

$2.7 \min$

$2.8 \min$
92

Y (89:11)

$Y(90: 10)$

73
Y (93:7)

One of the well-known advantages of flow chemistry is that scale-up of the reaction can be easily achieved by running the reaction continuously for a longer period of time. An additional benefit with regards to photochemistry in flow, is that the reactor dimensions and lamp setup can be optimized for a particular reaction as this dictates the amount of irradiance the reaction solution receives. Conversely, scaling a batch photochemical reaction would require a larger vessel that would suffer from poor penetration of light and overirradiation.

To adapt our pressure driven flow system to accommodate large volumes, an additional Duran pressure bottle was used in place of one of the solvent loops (figure 5 and Supplementary Information). The air pressure feed from the pressure control module was split between the larger solvent reservoir bottle on the top of the flow system and the smaller reagent bottle on the side. Once all tubing was primed with solvent, the tube feeding line B was manually switched from the solvent reservoir bottle to the reagent bottle. This meant that there would be no air in the system and the plug of reactant solution could be easily flushed through in its entirety by switching the flow to line A once the reagent bottle had emptied (Figure 5 and Supplementary Information). 


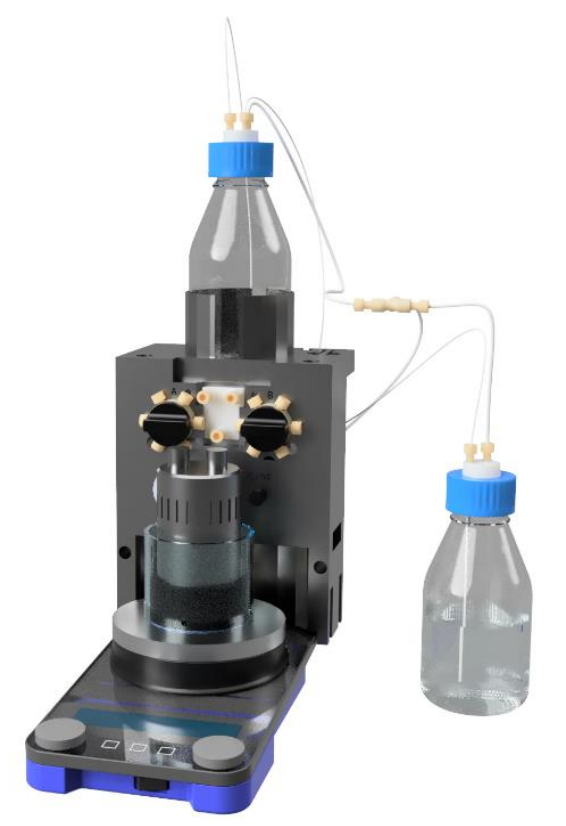

Figure 5 - Increased scale set-up, showing the arrangement of tubing to allow for increased volumes of reagents to pass through the system

In the first instance, the reaction was attempted with $50 \mathrm{~mL}$ of a $0.5 \mathrm{M}$ solution of reactants. As mentioned above, the capillary resistor was routinely flushed with acetone to remove any insoluble succinimide after each reaction. Unfortunately, this meant that when attempting to scale-up the reaction at the same concentration, it resulted in a reduction in flow rate from $5 \mathrm{~mL} / \mathrm{min}$ to $1.6 \mathrm{~mL} / \mathrm{min}$. The flow rate would return to normal after flushing of the capillary with acetone but this was not a practical solution for an extended run. This issue was solved by halving the concentration so that the succinimide would remain in solution. When the same reaction was attempted with a $0.25 \mathrm{M}$ solution, the flow rate was unchanged during the reaction and the product benzyl bromide was isolated in $89 \%$ yield, corresponding to a $78 \mathrm{mmol} \mathrm{h}^{-1}$ throughput.

In order to illustrate the benefits of conducting photochemical reactions in flow over batch, a comparison was carried out, where a solution of reactants were irradiated under the same conditions. As with the flow procedure, a $0.5 \mathrm{M}$ solution of methyl hydrocinnamate and NBS in acetonitrile was placed in a 2-5 mL microwave vessel (Biotage) and irradiated at a distance of $30 \mathrm{~mm}$. An aliquot taken after 27 seconds showed $36 \%$ conversion by HPLC, clearly demonstrating the benefits of continuous flow photochemistry. 


\section{Conclusion}

We have developed an inexpensive and adaptable photochemistry apparatus to be used with our pressure-driven flow chemistry system. Optimization of a bromination reaction was carried out using 3D printed polypropylene circular disc reactors that were adapted for photochemistry. The reaction proceeded well with a residence time of only 27 seconds. We were able to show the benefit of 3D printing polypropylene reactors for photochemistry and the ability to modify reaction paths for optimization. Scale-up of the photochemical bromination was carried out successfully with a throughput of $78 \mathrm{mmol} \mathrm{h}^{-}$

1. The effect of temperature on the reaction is currently being investigated and will be reported in due course. 


\section{Declarations}

The authors acknowledge funding from Zurich Insurance for the work carried out in this study which was given to fund MRP and collaboration with IKA in the development of the IKA FLOW continuous flow system. 


\section{References}

1. Bloom S, Liu C, Kölmel DK, Qiao JX, Zhang Y, Poss MA, Ewing WR, MacMillan DWC (2018) Decarboxylative alkylation for site-selective bioconjugation of native proteins via oxidation potentials. Nature Chem 10:205-211.

2. [T] Kim J, Li BX, Huang RY, Qiao JX, Ewing WR, MacMillan DWC (2020) SiteSelective Functionalization of Methionine Residues via Photoredox Catalysis. J Am Chem Soc 142:21260-21266.

3. Zhang X, MacMillan DWC (2017) Direct Aldehyde C-H Arylation and Alkylation via the Combination of Nickel, Hydrogen Atom Transfer, and Photoredox Catalysis. J Am Chem Soc 139:11353-11356.

4. Twilton J, Le C, Zhang P, Shaw MH, Evans RW, MacMillan DWC (2017) The merger of transition metal and photocatalysis. Nat Rev Chem 1:0052.

5. Barham JP, König B (2020) Synthetic Photoelectrochemistry. Angew Chem Int Ed 59:11732-11747.

6. Bonfield HE, Mercer K, Diaz-Rodriguez A, Cook GC, McKay BSJ, Slade P, Taylor GM, Ooi WX, Williams JD, Roberts JPM, Murphy JA, Schmermund L, Kroutil W, Mielke T, Cartwright J, Grogan G, Edwards LJ (2020) The Right Light: De Novo Design of a Robust Modular Photochemical Reactor for Optimum Batch and Flow Chemistry. ChemPhotoChem 4:45-51.

7. Schiel F, Peinsipp C, Kornigg S, Böse D (2021) A 3D-Printed Open Access Photoreactor Designed for Versatile Applications in Photoredox- and Photoelectrochemical Synthesis. ChemPhotoChem 5:431-437.

8. Lampkin PP, Thompson BJ, Gellman SH (2021) Versatile Open-Source Photoreactor Architecture for Photocatalysis Across the Visible Spectrum. Org Lett 23:5277-5281.

9. Wallner O, Mamonov K, Ortis F, Michel D, Michel M (2021) Assembly and Application of a Low Budget Photoreactor. Chemistry-Methods 1:240.

10. Rößler M, Liauw MA (2021) The PhotoFlexys: A Multi-Purpose Reactor Platform to Simplify Process Intensification and Mechanistic Studies in Photochemistry. Chemistry-Methods 1:261. 
11. Winkler $C K$, Simić $S$, Jurkaš $V$, Bierbaumer $S$, Schmermund L, Poschenrieder S, Berger SA, Kulterer E, Kourist R, Kroutil W (2021) Accelerated Reaction Engineering of Photo(bio)catalytic Reactions through Parallelization with an Open-Source Photoreactor. ChemPhotoChem doi/10.1002/cptc.202100109.

12. Clark CA, Lee DS, Pickering SJ, Poliakoff M, George MW (2018) UV PhotoVap: Demonstrating How a Simple and Versatile Reactor Based on a Conventional Rotary Evaporator Can Be Used for UV Photochemistry. Org Process Res Dev 22:595-599.

13. Le C, Wismer MK, Shi Z-C, Zhang R, Conway DV, Li G, Vachal P, Davies IW, MacMillan DWC (2017) A General Small-Scale Reactor To Enable Standardization and Acceleration of Photocatalytic Reactions. ACS Cent Sci 3:647-653.

14. Bonfield HE, Knauber T, Lévesque F, Moschetta EG, Susanne F, Edwards LJ (2020) Photons as a 21 ${ }^{\text {st }}$ century reagent. Nat Commun 11:804.

15. Williams JD, Kappe CO (2020) Recent advances toward sustainable flow photochemistry. Curr Opin Green Sustain Chem 25:1000351.

16. Rehm TH (2020) Flow Photochemistry as a Tool in Organic Synthesis. Chem Eur J 26:16952-16974.

17. Rehm TH (2020) Reactor Technology Concepts for Flow Photochemistry. ChemPhotoChem 4:235-254.

18. Cambié D, Bottecchia C, Straathof NJW, Hessel V, Noël T (2016) Applications of Continuous-Flow Photochemistry in Organic Synthesis, Material Science, and Water Treatment. Chem Rev 116:10276-10341.

19. Su Y, Straathof NJW, Hessel V, Noël T (2014) Photochemical Transformations Accelerated in Continuous-Flow Reactors: Basic Concepts and Applications. Chem Eur J 20:10562-10589.

20. Elliott LD, Knowles JP, Koovits PJ, Maskill KG, Ralph MJ, Lejeune G, Edwards LJ, Robinson RI, Clemens IR, Cox B, Pascoe DD, Koch G, Eberle M, Berry MB, Booker-Milburn KI (2014) Batch versus Flow Photochemistry: A Revealing Comparison of Yield and Productivity. Chem Eur J 20:15226-15232. 
21. Renner M, Griesbeck A (2020) Think and Print: 3D Printing of Chemical Experiments. J Chem Educ 97:3683-3689.

22. Santandrea J, Kairouz V. Collins SK (2018) Continuous Flow Science in an Undergraduate Teaching Laboratory: Photocatalytic Thiol-Ene Reaction Using Visible Light. J Chem Educ 95:1073-1077.

23. Contreras-Cruz DA, Cantú-Reyes M, García-Sánchez JM, Peña-Ortíz D, Sánchez-Carmona MA, Miranda LD (2019) Shedding Blue Light on the Undergraduate Laboratory: An Easy-to- Assemble LED Photoreactor for Aromatization of a 1,4- Dihydropyridine. J Chem Educ 96:2015-2020.

24. Volpe K, Podlesny EE (2020) Modernization of a Photochemical Reaction for the Undergraduate Laboratory: Continuous Flow Photopinacol Coupling. J Chem Educ 97:586-591.

25. Rao ZX, Patel B, Monaco A, Cao ZJ, Barniol-Xicota M, Pichon E, Ladlow M, Hilton ST (2017) 3D-Printed Polypropylene Continuous-Flow Column Reactors: Exploration of Reactor Utility in SNAr Reactions and the Synthesis of Bicyclic and Tetracyclic Heterocycles. Eur. J. Org. Chem.:6499-6504.

26. Penny MR, Hilton ST (2020) Design and Development of 3D Printed Catalytically Active Stirrers for Chemical Synthesis. React. Chem. Eng. 5:853858.

27. Penny, MR, Rao, ZX, Ishaq A; Thavarajah R, Hilton, S (2020): 3D Printed Tetrakis(triphenylphosphine)palladium (0) Impregnated Stirrer Devices for Suzuki-Miyaura Cross-Coupling Reactions. ChemRxiv. Preprint. https://doi.org/10.26434/chemrxiv.12798545.v1.

28. Penny, M.R., Tsui, N. \& Hilton, S.T. (2021) Extending practical flow chemistry into the undergraduate curriculum via the use of a portable low-cost 3D printed continuous flow system. J Flow Chem 11, 19-29.

29. Penny MR, Rao ZX, Peniche BF, Hilton ST (2019) Modular 3D printed compressed air driven continuous-flow systems for chemical synthesis. Eur $\mathrm{J}$ Org Chem 2019:3783-3787. 
30. Cantillo D, de Frutos O, Rincon JA, Mateos C, Kappe CO (2014) A Scalable Procedure for Light-Induced Benzylic Brominations in Continuous Flow. J Org Chem 79:223-229.

31. Rastelli EJ, Yue D, Millard C, Wipf P (2021) 3D-printed cartridge system for inflow photo-oxygenation of 7-aminothienopyridinones. Tetrahedron 79:131875. 